\title{
Use of Electro-Chemical Process for Waste Sludge Generated from Moving Bed Bioreactor
}

\author{
Shohreh Azizi and Nomathamsaqa P. Sithebe
}

\begin{abstract}
The rapid population growth in South Africa has increased the requirement of waste water treatment facilities. This study was conducted to assess the moving bed bio reactor receiving from Mafikeng sewage treatment plant. The experiment was undertaken on a continue laboratory scale and analytical data was collected before and after treatment. The reduction of 83.21 $\mathrm{COD}, 87.64 \mathrm{BOD}$ was achieved in optimum Hydraulic retention time. The efforts also made an attention into potential technology for waste sludge reduction. The study was undertaken the use of electrochemical process as pre-treatment for waste sludge. It is observed $60 \%$ of digestion period was decreased through the Electro-chemical treatment.

Basic data obtained through the experimental research are demonstrated that the MBBR may be used in an extremely compact high-rate process $(<3 \mathrm{~h}$ total HRT) for secondary treatment process and the combination of electrochemical and aerobic digestion system is proposed to overcome all the disadvantages of aerobic and anaerobic digestion system. The complete system offers a most advance and improved sewage treatment plant.
\end{abstract}

Index Terms-Moving bed bioreactor, digestion time, electrochemical, aerobic digestion.

\section{INTRODUCTION}

Rapid urbanization and industrialization throughout the world has increased the requirement of water. Therefore, wastewater treatment facilities are becoming essential. Urbanization has resulted in generation of massive quantum of domestic sewage and its treatment is mandatory in most of the industrially developed regions of the world. The domestic sewage treatment plants are centered to biological process and have received highest popularity due to its economic viability [1], [2].

Over the past century, the biological treatment has been based on two distinct principles termed as suspended biomass and attached biomass processes [1].

The activated sludge process has been the most widely used treatment method. It accounts for over $90 \%$ of the municipal waste water treatment plant [3]. However, the activated sludge system is difficult to be controlled due to complex operation, thereof [4], [5].

Hence it is crucial to find an alternative treatment system

Manuscript received August 28, 2014; revised October 15, 2014

Shohreh Azizi is with the Department of Biological Sciences, Faculty of Agriculture, Science and Technology, North-West University, Mafikeng Campus, Private Bag X2046, Mmabatho 2735, South Africa (Corresponding author; e-mail: shohrehazizi1379@gmail.com). in order to overcome these drawbacks and achieve the most efficient treatment system to remove organic material along with microbial growth and activity [6].

In recent years, there has been constantly a growing interest in attached growth biological system for domestic wastewater treatments. The moving bed bioreactor is one of the latest developments in a class of reactors situated in the spectra of wastewater treatment between activated sludge and fixed-film biofilters [7], [8]. Biofilm is attached to the carrier elements that move freely along with the water in the reactor. Biofilms have the potential to have greater treatment efficiency on low concentration of wastewaters than activated sludge units due to accumulation of higher microbial population in presence of higher surface area [9], [10]. The major factors that affect the attached growth in the biological process are the hydraulic retention time, biofilm growth and thickness; media surface area, media volume in the reactor, oxygen concentration in the reactor and effluent characteristics [11], [12]. In comparison with activated sludge systems, the attached growth biological systems typically require a smaller footprint and are less dependent on final sludge separation [2], [13]. Attached growth biological systems are usually less energy-intensive, more resistant to shock loadings, capable to take changes in process parameters and also have a higher removal rate of organic pollutants per unit volume [14].

\section{A. Sludge Generation and Associated Problems in Biological Treatment System}

The primary problem associated with any of the aerobic process is the production of huge quantities of sludge generated as an undigested or semi digested byproduct [15].

The reduction of waste sludge has been a serious disposal problem due to regulating, economic and environmental issues [16].

The aerobic digestion process is however the most popular method as through this process low quantity, mineralized, well-settled, easy thickening and dewatered sludge can be obtained [17]. During the aerobic digestion considerable changes occur in the structure of sludge properties and some physical features directly affect the sludge digestion [18].

Sludge handling, treatment and disposal are complex, owing to the offensive constituents present, which vary with the source of waste-water and the treatment processes applied [19]. The aerobic digestion system however, challenges with the drawbacks of high operating cost, energy consumption and high digestion period. Therefore, it is significant to overcome the drawbacks by reducing digestion time and increasing the efficiency. Over the years Electro-oxidation or electro-destruction has been used for degradation of organics at high-voltage electrical currents [19]. The high voltage 
currents facilitates the formation of hydroxyl radicals though water splitting. Hydroxyl radicals are considered to be the most powerful oxidizing agent after fluorine. In this experiment an attempt has been made to use the same concept for sludge digestion.

The purpose of this study is to evaluate MBBR concept for Mafikeng sewage treatment plant and explore the feasibility of application of such an electro-chemical process as pretreatment for sludge generated from the system. It is envisaged that such systems could be helpful in Mafikeng sewage treatment plant where less operating space is available and can offer small foot print area and hassle free operations. MBBR with the help of electro chemical as pretreatment of sludge can be used for designing a robust treatment system.

\section{MATERIAL AND METHODS}

\section{A. Pilot Plant Setup}

A small horizontal flow based moving bed bioreactor was designed and operated in the premises of Department of Biological sciences, North-West University, South Africa as per the schematic presentation in Fig. 1.

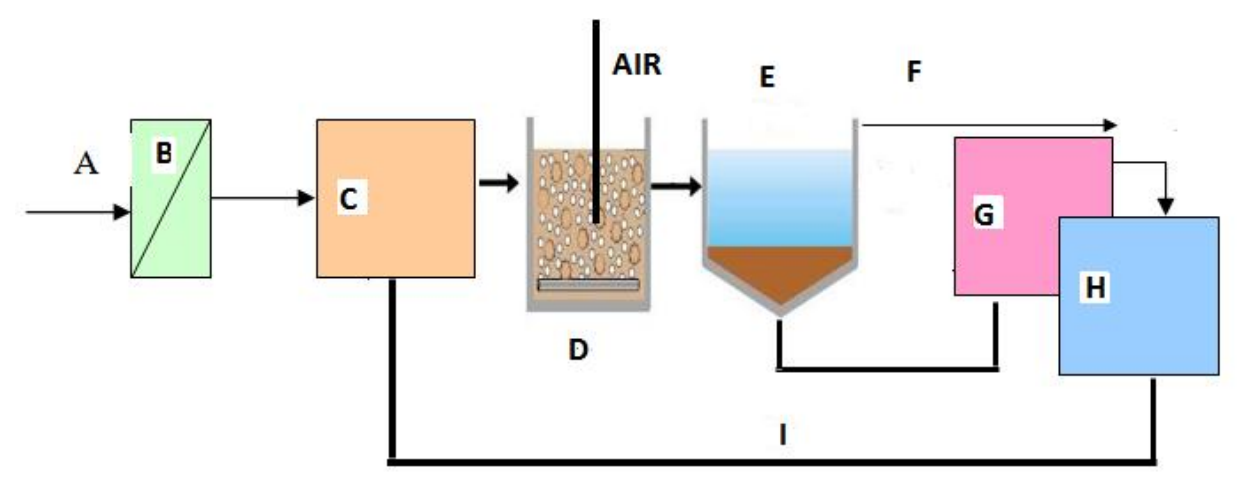

A - Influent Sewage, B - Primary screening, C - Equalization tank, D - Moving bed reactor, E - Clarifier, F - Treated water, G - Electrochemical cell for sludge pre-treatment, $\mathrm{H}$ - Aerobic digester, I - Return of water after sludge digestion

Fig. 1. The schematic diagram of moving bed bio reactor with the combination of electrochemical and aerobic digestion.

This unit was used to evaluate the performance of moving bed process for wastewater from Mafikeng sewage treatment plant.

\begin{tabular}{lc} 
TABLE I: DIMENSIONAL DETAILS OF MOVING BED BIOREACTOR \\
\hline Area of the reactor & $0.23 \mathrm{~m}^{2}$ \\
\hline Volume of the Reactor & $116 \mathrm{~L}$ \\
Height of the reactor $(\mathrm{mm})$ & 500 \\
Void volume in presence of media & $63 \mathrm{lit}$ \\
Settler Volume & $25.4 \mathrm{~L}$ \\
\hline
\end{tabular}

The size and dimension of the pilot plant is mentioned in the Table I. The moving bed bioreactor was operated as MBBR system [2]. The mech aperture size of 2 was used the raw waste water from sewage treatment plant entered to primary screening. In the aeration tank, microorganisms on the media were responsible to degrade waste water under aerobic condition. In this experiment also cylindrical shaped polypropylene was used to support biofilm growth (Table II). The electro chemical cell was used as sludge pretreatment.

It consists of an anode and cathode. Titanium electrode coated with mixed precious metal oxide of Ruthenium and Iridium was used as anode and Stainless steel electrode was used as cathode. The anode is dimensionally stable due to titanium and is not leachable by applied current. The current was passed through the anode to facilitate the electrochemical reaction. The gap between two electrodes is kept $30 \mathrm{~mm}$ to reduce the voltage. The electrode area of anode and cathode are $600 \mathrm{~mm}^{2}$ [19].

\section{B. Sampling and Analysis}

The domestic wastewater samples were collected from Mafikeng sewage on a daily basis for extensive experiments and the evaluation of the system.

The analysis of sludge characteristic which was produced from the system was analyzed.

Samples from the inlet and outlet of MBBR system were analyzed for $\mathrm{COD}, \mathrm{BOD}_{5}, \mathrm{NH}_{3}-\mathrm{N}, \mathrm{PO}_{4}-\mathrm{P}$ and most probable number (MPN) of coliform bacteria as per standard methods [20].The mixed-liquor suspended solids (MLSS), mixed liquor volatile suspended solids (MLVSS) and sludge volume index (SVI) of sludge waste were examined through the standard practices[20], [21]. The SCOD was analyzed by the open reflux method.The particle size was determined by laser diffraction method (Malvern Master size 2000,UK) [19].

\section{RESUlT AND DisCUSSION}

\section{A. Details of Carrier Media}

\begin{tabular}{ll} 
TABLE II: THE DETAILS OF CARRIER MEDIA FEATURE \\
\hline Materials & Polypropylene \\
\hline $\begin{array}{l}\text { Density }\left(\mathrm{g} / \mathrm{cm}^{3}\right) \\
\text { Shape }\end{array}$ & $\begin{array}{l}0.83 \\
\text { rednilyC devoorG }\end{array}$ \\
Length & 10 \\
Diameter & 14 \\
Specific surface $\left(\mathrm{m}^{2} / \mathrm{m}^{3}\right)$ & 450 \\
Fill ratio & 50
\end{tabular}

Carrier media is essential for bacterial attachment and growth and would require roughness and porosity on the surface. The characteristic of carrier media is also depends on the density and the diameter of the support. The available 
surface area is very critical for effective microbial growth. The carrier media used during the studies was made up of Poly propylene having surface area approximately $450 \mathrm{~m}^{2} / \mathrm{m}^{3}$ and. The carrier media is provided with grooves on the outside to protect biofilm loss and promote grow of biofilm. In this study indicated that $50 \%$ of media fill ratio (V/V) was selected as optimum for this study (see Table II).

\section{B. Evaluation of the Hydraulic Retention Time $(H R T)$ in the System}

Optimization of HRT is an important parameter for the treatment of sewage which indicates the rate of organic removal when the uncertainty persists on account of effective surface area of the carrier media. The variation in the hydraulic load and measuring the outlet parameters is an easy method of assessing the performance of a system. The effect of different hydraulic retention time on the performance of the reactor system was studied and an optimum hydraulic retention time was evaluated. The flow rate of the system was varying by keeping 2 to $10 \mathrm{hrs}$ hydraulic retention time. The carrier media filling ration was kept at $50 \%$ as an optimized level as high media filling ratio there has been no substantial improvement in treatment efficiency. The BOD loading of 5.9541 to 31.677 (g/day) was found at various HRTs (Table III). Removal of COD and BOD concentration were correlated with the efficiency at various hydraulic retention times.

TABLE III: EXPERIMENTAL CONDITIONS AT DIFFERENT HYDRAULIC

\begin{tabular}{cccc}
\hline $\begin{array}{c}\text { LOADING } \\
(\mathrm{hr})\end{array}$ & $\begin{array}{c}\text { Initial BOD } \\
(\mathrm{mg} / \mathrm{L})\end{array}$ & $\begin{array}{c}\text { BOD Removed } \\
(\mathrm{mg} / \mathrm{L})\end{array}$ & $\begin{array}{c}\text { Reduction at outlet } \\
(\%)\end{array}$ \\
\hline 10 & $294.2 \pm 12.18$ & $273.92 \pm 11.12$ & 93.13 \\
8 & $303.04 \pm 10.88$ & $280.25 \pm 10.50$ & 92.48 \\
6 & $289 \pm 18.63$ & $262.04 \pm 17.28$ & 90.67 \\
4 & $302.6 \pm 11.19$ & $273 \pm 10.56$ & 90.22 \\
3 & $272.8 \pm 8.05$ & $239.08 \pm 7.80$ & 87.64 \\
2 & $283.41 \pm 4.94$ & $241.81 \pm 4.52$ & 85.32 \\
\hline
\end{tabular}

The values represent the mean of five replicates \pm standard errors (SE)

The Fig. 2 indicates COD concentration of treated effluent is below $100 \mathrm{mg} / \mathrm{L}$ respectively at a hydraulic retention time of above 3 hrs. At below 3 hrs the COD concentration of treated effluent increased to above $100 \mathrm{mg} / \mathrm{L}$. Based on the finding, $3 \mathrm{hrs}$ is selected as an optimum HRT for sewage treatment under standard condition. At optimum HRT the average COD and BOD reduction was found $83.21 \%$ and $87.64 \%$ respectively. The efficiency of the system is due to better oxygen transfer efficiency through mass transfer and higher microbial growth on the surface of carrier media. This is also on account of high rate of organic assimilation at $3 \mathrm{hrs}$ HRT.

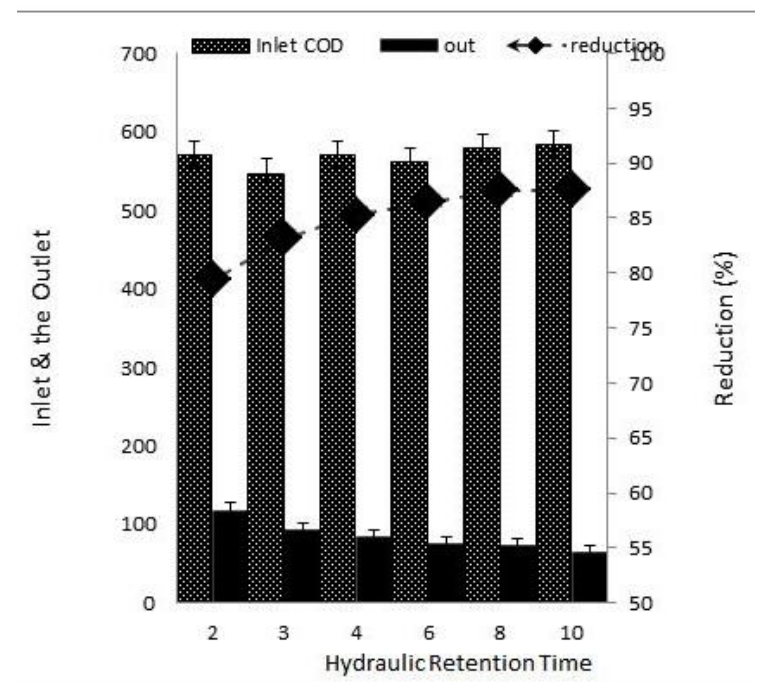

Fig. 2. Average COD values of the inlet and outlet by moving bed bioreactor.

\section{Estimation of Physico-Chemical Parameter}

The overall performance of the system shows that at an optimum HRT of $3 \mathrm{hrs}$ and maintaining other process conditions were achieved as shown in Table IV. The concentration of TVC at the outlet and the carrier media was found with an average $3.87 \times 107 \mathrm{cfu} / \mathrm{cm}^{2}$ and $3.107 \times 10^{5}$ $\mathrm{cfu} / \mathrm{cm}^{2}$. The average reduction of MPN was $93.2 \%$. The system was operated over a period of 2 months at optimum process conditions and the results are consolidated mean values of the study. The result shows the MBBR can reduce the overall foot print area of the system due to low HRT and would require low operation and maintenance. The overall organic loading on carrier media is worked out to be 0.048 $\mathrm{kg} / \mathrm{m}^{2} / \mathrm{m}^{3}$ at optimum operating conditions.

\begin{tabular}{cccc}
\multicolumn{2}{c}{ TABLE IV: THE AVERAGE OF PHYSIC-CHEMICAL PARAMETER FROM THE MOVING BED BiOREACTOR } \\
\hline Parameters & Inlet & Outlet & Reduction at Outlet $(\%)$ \\
\hline COD $(\mathrm{mg} / \mathrm{L})$ & $548.6 \pm 11.91$ & $92.1 \pm 3.46$ & 83.21 \\
BOD $(\mathrm{mg} / \mathrm{L})$ & $272.8 \pm 11.05$ & $33.71 \pm 2.34$ & 87.64 \\
TDS $(\mathrm{mg} / \mathrm{L})$ & & & \\
$\mathrm{NH}_{3}-\mathrm{N}(\mathrm{mg} / \mathrm{L})$ & $602 \pm 39.69$ & $412.83 \pm 26.90$ & 31.41 \\
$\mathrm{PO}_{4}-\mathrm{P}(\mathrm{mg} / \mathrm{L})$ & $38.23 \pm 3.52$ & $9.17 \pm 1.34$ & 76.01 \\
\hline
\end{tabular}

The values represent the mean of five replicates \pm standard errors (SE)

\section{Biomass on Media and in Suspension}

In the moving bed bioreactor the biomass grow as a bioflim on the carrier media with large protected surface area. The biofilm are well protected against all variations including organic loading and toxic compounds. The biomass is generated inside the media carrier was estimated and around $9000-9500 \mathrm{mg} / \mathrm{L}$ and in suspension it was around 350-400 $\mathrm{mg} / \mathrm{L}$ measured as Mixed liquor suspended solids (MLSS). This indicates that the biomass present in the suspension is mostly due to biomass sloughed from carrier media an account of bacterial decay. 


\section{E. The Characteristic of Waste Sludge from System}

The waste sludge from the system was examined under batch aerobic digestion the concentration of mixed liquor suspended solid and mixed liquor volatile suspended solid was studied from the Table $\mathrm{V}$, the decrease in MLSS was $90.02 \%$ of the primary value of sludge after digestion period .The value of MLVSS of the sludge from MBBR before going through aerobic digestion was $56 \%$ of MLSS indicating semi digested sludge. The result shows that the waste sludge digestion took 11 days due to high digestion time, Fig. 3. There for it would require large land area which it's not suitable option for waste treatment plant.

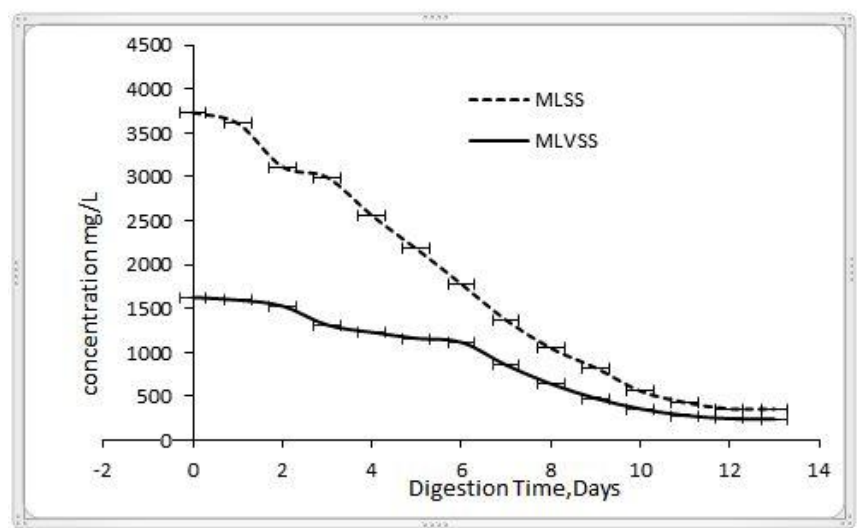

Fig. 3. Variation in MLSS and MLVSS during Batch aerobic digestion.

\begin{tabular}{cccc}
\multicolumn{2}{c}{ TABLE V: THE CHARACTERISTICS OF WASTE SLUDGE FROM MBBR } \\
\hline MLSS & MLVSS & SVI & $\begin{array}{l}\text { Particle } \\
\text { Size } \boldsymbol{\mu m}\end{array}$ \\
\hline $\mathbf{3 7 3 2} \pm \mathbf{2 5 3}$ & $\mathbf{1 6 2 8} \pm \mathbf{1 4 8}$ & $\mathbf{8 7} \pm \mathbf{1 2}$ & $\mathbf{3 0 - 1 4 0}$ \\
\hline
\end{tabular}

\section{F. Use of Electrochemical Process in Waste Sludge}

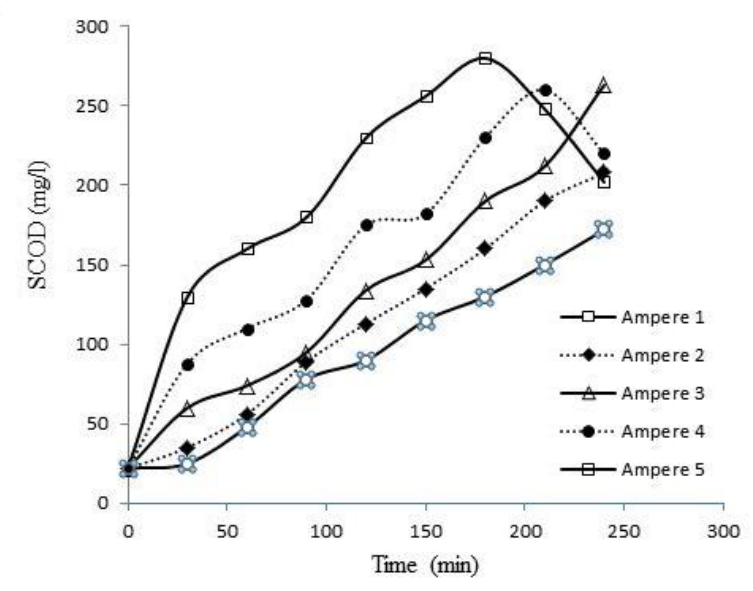

Fig. 4. Soluble COD profile at different ampere.

The study was conducted using waste sludge from MBBR system under batch condition. In the laboratory scale electrochemical reactor, electrical current was applied from 1 to 5amperes per liter and sludge digestion was measured by measuring the sludge concentration and soluble COD concentration. During sludge digestion the secondary metabolites increase in liquid suspension due to disintegration of cell. The reaction time was varied at different applied current. The results indicate that the soluble COD concentration was steadily increased with each applied current. At higher applied current (amp) the COD concentration increased at faster rate indicating that cell disintegration happens at faster rate. At higher applied current the increase in soluble COD level starts within 30 mins whereas at lower applied current the phenomena proceeds at slower rate. These results show that the applied current is generating oxidant which is oxidizing the cellular material. The results show that higher current is function of higher oxidant generation. The results are presented Fig. 4.

Experiments were carried out to assess complete oxidation and mineralization of sludge material. The results in Fig. 4 shows that after $3 \mathrm{hrs}$ the soluble concentration is dropping at 5 amp applied current. The same phenomenon is happening in each applied current. Experiments above 3 ampere ( 4 \& 5 amp) show increase in water temperature, reaching to near boiling temperature. Keeping this in view, applied current of 3 ampere was used to assess the complete degradation of cellular material. The results indicate that it took $20 \mathrm{hrs}$ for complete degradation of cellular material and mineralization is shown Fig. 5 [19].

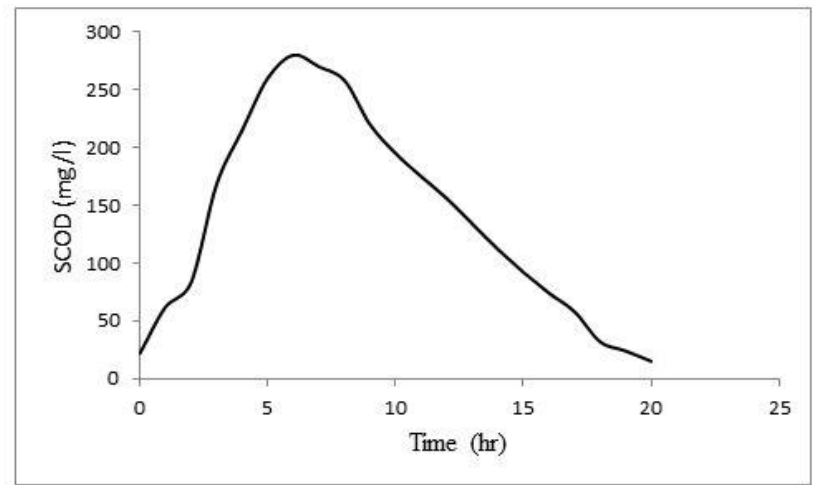

Fig. 5. The soluble COD profile at $3 \mathrm{amp}$ applied current.

The electrochemical process cannot be used as stand-alone solution due to the operating and capital cost for sludge digestion, unless its applied for sludge pretreatment [19].

The experimental data (Fig. 5) indicates that the during initial sludge digestion the intra cellular materials from sludge comes out due to the electrical current. The electrochemical oxidation possibly ruptures the cell wall [22] and facilitates the release of intracellular matter to the aqueous phase.

This is evident from the results obtained on soluble COD levels at all operating amperage. These results indicate that at 3 ampere applied current the soluble COD increases till $4 \mathrm{hrs}$ and subsequently decreases with time. Further decomposition of soluble COD proceeds slowly indicating a slow oxidation of the organics by electrochemical reaction; hence the overall operating cost increases at longer reaction time. The results indicate that such process accelerated the subsequent aerobic degradation and reduce the retention time needed during aerobic digestion. The results showed that sludge digestion is possible within 5 days as compare to the conventional aerobic sludge digestion time of 11 days for the waste sludge generated from moving bed bio reactor.

The experimental result of aerobic sludge digestion after electrochemical preconditioning is presented in Fig. 6. The results showed that overall $93.21 \%$ reduction in MLSS concentration from the combination of electrochemical and 
results showed that overall $93.21 \%$ reduction in MLSS concentration from the combination of electrochemical and aerobic digestion process.

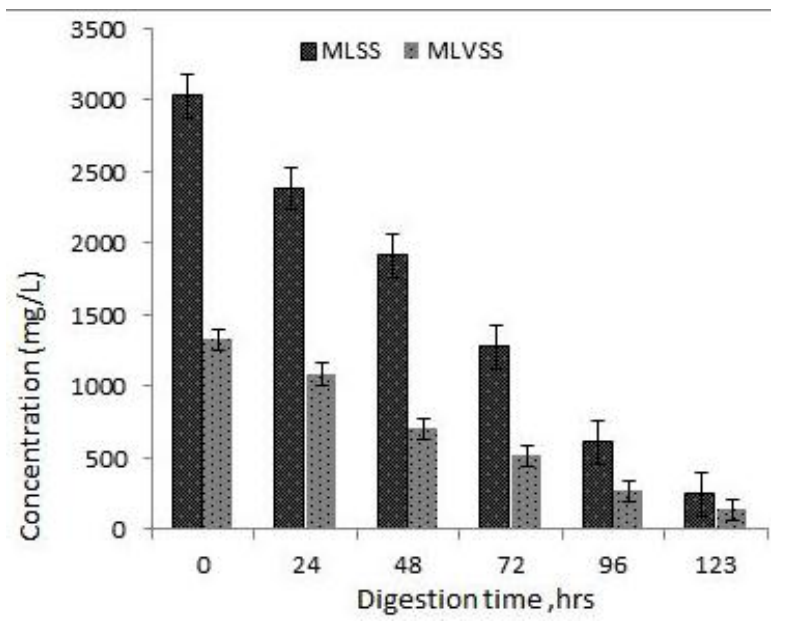

Fig. 6. Variations of MLSS \& MLVSS in electrochemical pre-treatment in moving bed bioreactor in batch system.

It can be concluded that the waste sludge can be tacked with an electrochemical pretreatment stage followed by an aerobic sludge digestion process. The electrochemical pre-treatment stage can reduce the digestion time by over $80 \%$ than conventional aerobic sludge digestion process.

\section{ACKNOWLEDGMENT}

The authors are thankful to the department of Biological sciences, North-west University, Mafikeng Campus, South Africa.

\section{REFERENCES}

[1] T. Stephenson, A. Mann, and J. Upton, "The small footprint Wastewater treatment process," Chemistry and Industry, vol. 14, no. 4, p. $533,1993$.

[2] S. Azizi, A. Valipour, and T. Sithebe, "Evaluation of different wastewater treatment processes and development of a modified attached growth bioreactor as a decentralized approach for small communities," The Scientific World Journal, 2013.

[3] Y. Liu, "Chemically reduced excess sludge production in the activated sludge process," Chemosphere, vol. 50, no. 1, pp. 1-7, 2003.

[4] B. Holenda et al., "Dissolved oxygen control of the activated sludge wastewater treatment process using model predictive control," Computers \& Chemical Engineering, vol. 32, no. 6, pp. 1270-1278, 2008.

[5] P. Cozma and M. Gavrilescu, "Airlift reactors: Applications in wastewater treatment," Environmental Engineering and Management Journal, vol. 11, no. 8, pp. 1505-1515, 2012.
[6] N. Mehrdadi et al., "Determination of design criteria of an H-IFAS reactor in comparison with an extended aeration activated sludge process," Iranian Journal of Environmental Health Science \& Engineering, vol. 3, no. 1, pp. 53-64, 2006.

[7] J. Heijnen et al., "Development and scale-up of an aerobic biofilm air-lift suspension reactor," Water Science \& Technology, vol. 27, no. 5-6, pp. 253-261, 1993.

[8] M. Maurer et al., "Moving-bed biological treatment (MBBT) of municipal wastewater: denitrification," Water Science and Technology, vol. 43, no. 11, pp. 337-344, 2001.

[9] S. Iwai and T. Kitao, Wastewater Treatment with Microbial Films, Technomic Lancaster, PA, 1994.

[10] B. E. Rittmann and P. L. McCarty, Environmental Biotechnology: Principles and Applications, Tata McGraw-Hill Education, 2012

[11] B. Rusten and T. Westrum, "A new moving bed biofilm reactor-applications and results," Water Science and Technology, vol. 29, no. 10-11, pp. 157-165, 1994.

[12] B. Rusten, O. Kolkinn, and H. Odegaard, "Moving bed biofilm reactors and chemical precipitation for high efficiency treatment of wastewater from small communities," Water Science and Technology, vol. 35 , no. 6 , pp. 71-79, 1997.

[13] M. Rodgers, "Organic carbon removal using a new biofilm reactor," Water Research, vol. 33, no. 6, pp. 1495-1499, 1999.

[14] M. A. S. Chaudhry and S. A. Beg, "A review on the mathematical modeling of biofilm processes: advances in fundamentals of biofilm modeling," Chemical Engineering \& Technology, vol. 21, no. 9, pp. 701-710, 1998.

[15] M. Weemaes et al., "Ozonation of sewage sludge prior to anaerobic digestion," Water Science \& Technology, vol. 42, no. 9, pp. 175-178, 2000.

[16] Y. Wei et al., "Minimization of excess sludge production for biological wastewater treatment," Water Research, vol. 37, no. 18, pp. 4453-4467, 2003.

[17] R. Hartman et al., "Sludge stabilization through aerobic digestion," Water Pollution Control Federation Journal, pp. 2353-2365, 1979.

[18] L. Olböter and A. Vogelpohl, "Influence of particle size distribution on the dewatering of organic sludges," Water Science \& Technology, vol. 28, no. 1, pp. 149-157, 1993

[19] S. Azizi et al., "Performance evaluation of the electrolysis process for waste sludge stabilization in decentralization practices," Desalination and Water Treatment, pp. 1-8, 2014.

[20] A. Apha, Standard Methods for the Examination of Water and Wastewater, APHA, AWWA. and WEF Publishing, Washington, DC, 2005.

[21] L. Metcalf, G. Tchobanoglous et al., Wastewater Engineering: Treatment, Disposal, and Reuse, McGraw-Hill, New York, USA, 2004.

[22] K. Rabaey et al., "Microbial ecology meets electrochemistry: electricity-driven and driving communities," The ISME Journal, vol. 1, no. 1, pp. 9-18, 2007.

Shohreh Azizi was born in Kermanshah province, Iran in April 1980. She was teaching in University of Razi, Agriculture and Natural Resources Faculty in Kermanshah Iran from September 2011 to December 2012. She had collaboration with University of Bahrian with the research project studies on the performance of Phragmaties for sewage waste water treatment 